\title{
CARACTERÍSTICAS ESTRUTURAIS E BROMATOLÓGICAS DO CAPIM TANZÂNIA SOB PASTEJO ISOLADO, SIMULTÂNEO E ALTERNADO DE OVINOS COM BOVINOS
}

\author{
VIVIANE RODRIGUES VERDOLIN DOS SANTOS ${ }^{1}$, HELDER LOUVANDINI ${ }^{2}$, CONCEPTA MARGARET \\ MCMANUS PIMENTEL $^{3}$, DAIANA LIMA BRITO ${ }^{4}$ \\ ${ }^{1}$ Pesquisadora Doutora Embrapa Pesca e Aquicultura, Palmas, TO - viviane.santos@embrapa.br \\ ${ }^{2}$ Professor Doutor do Centro de Energia Nuclear na Agricultura, Piracicaba, SP. \\ ${ }^{3}$ Professora Doutora Universidade Federal do Rio Grande do Sul, Porto Alegre, RS. \\ ${ }^{4}$ Graduanda em Medicina Veterinária da Universidade de Brasília, Brasília, DF.
}

\begin{abstract}
Objetivou-se avaliar o efeito dos três sistemas de pastejo rotacionado: isolado ( $\mathrm{O}$ - pastejo isolado de ovinos), simultâneo (BO - pastejo simultâneo de bovinos com ovinos no mesmo piquete) e alternado (BDO - pastejo alternado: primeiro pelos bovinos, depois pelos ovinos), sobre características estruturais e bromatológicas do capim Tanzânia. O delineamento foi inteiramente casualizado, em fatorial 3x3 (sistemas de pastejo $\mathrm{x}$ ciclos de pastejo). Utilizaram-se 12 bovinos (mestiços), com peso médio de $207 \mathrm{~kg}, 16$ ovelhas adultas com $47 \mathrm{~kg}$ e 30 cordeiros com peso médio de $23 \mathrm{~kg}$ da raça Santa Inês. As seguintes variáveis foram avaliadas: massa de forragem disponível por ciclo de pastejo (MFP); proporções de folhas $(\mathrm{PF})$, colmo (PC) e material morto (PMM); relação
\end{abstract}

PALAVRAS-CHAVE: gramínea; pastagem; ruminantes. folha:colmo (F/C); teores de matéria seca (MS), matéria mineral $(\mathrm{MM})$, proteína bruta $(\mathrm{PB})$, extrato etéreo $(\mathrm{EE})$, fibra em detergente neutro (FDN), fibra em detergente ácido (FDA), fósforo inorgânico (Pi) e nutrientes digestíveis totais (NDT). Os tratamentos $\mathrm{BO}$ e $\mathrm{O}$ apresentaram menores valores para as variáveis $\mathrm{PC}$ e $\mathrm{FDN}$, ao mesmo tempo em que foram superiores em $\mathrm{F} / \mathrm{C}$, $\mathrm{PB}, \mathrm{EE}$ e NDT em relação ao tratamento BDO, denotando melhor qualidade do capim oferecido aos ovinos nesses dois tratamentos. Nas demais variáveis não houve efeito dos sistemas e nem dos ciclos de pastejo. O sistema de pastejo simultâneo pode ser considerado uma alternativa de manejo ao sistema isolado de ovinos na região de cerrado brasileiro.

\section{STRUCTURAL AND CHEMICAL TRAITS OF TANZANIA GRASS UNDER ISOLATED, SIMULTANEOUS AND ALTERNATED GRAZING BY SHEEP AND CATTLE}

\section{ABSTRACT}

The aim of this study was to evaluate the effect of three types of rotational pasture: isolated (I - grazing only by sheep), simultaneous ( $\mathrm{S}$ - simultaneous grazing by cattle and sheep) and alternated (A - granzing by cattle and then by sheep) on the structural and chemical traits of grass. Twelve crossbreed heifers, weighing initially $207 \mathrm{~kg}, 30$ Santa Inês lambs, weighing $23 \mathrm{~kg}$, and 16 adult ewes weighing $47 \mathrm{~kg}$ were used. The following parameters were determined on the pasture: forage mass available per grazing cycle (FMC); proportion of leaf (PF); stalk (PS); dead material (PDM), leaf:stalk ratio (L/S); levels of dry matter (DM); mineral matter (MM); crude protein (PB); ether extract (EE); neutral detergent fiber (NDF); acid detergent fiber (ADF); inorganic phosphorus (Pi) and total digestible nutrients (TDN). The $\mathrm{S}$ and I systems presented the smallest values for PS and NDF, while their values for L/S, CP, EE and TDN were higher than in A system. Therefore, the results showed that the grass offered to sheep in S and I systems had better quality than in the A system. There was not effect of systems and cycles of pasture on the others parameters evaluated. Tanzania grass available to sheep showed best structural and chemical 
traits in S and I systems while it presented worse quality in A system. The $\mathrm{S}$ system may be an alternative to

KEYWORDS: grass; pasture; ruminant.

\section{INTRODUÇÃO}

As pastagens constituem a principal fonte de alimento para o rebanho brasileiro de ruminantes domésticos, o que tem propiciado elevada competitividade do Brasil no mercado internacional de carne e leite, em razão do baixo custo de produção, especialmente com alimentação. Na produção animal em pastejo, além do valor nutritivo do pasto, a sua estrutura também afetará a resposta do animal, em termos de consumo e desempenho (CARVALHO et al., 2001; POMPEU et al., 2008), além de influir na eficiência de utilização dos recursos abióticos, interferindo na competição entre plantas (LEMAIRE, 2001; CARVALHO et al., 2005).

A qualidade da forragem é determinada pelas características químicas e físicas das plantas, sendo que as interações destas com os mecanismos de digestão, metabolismo e controle do consumo voluntário determinam o nível de ingestão de energia digestível, bem como o desempenho animal. Nesse sentido, conhecer a composição química das plantas forrageiras possibilita quantificar a presença de compostos como proteína, carboidratos estruturais, carboidratos solúveis, substâncias tóxicas, ácidos orgânicos, vitaminas e minerais essenciais para os animais. Assim, é possível formular rações que atendam às necessidades nutricionais dos animais (REIS \& RODRIGUES, 1993).

O potencial da cultivar Tanzânia pode ser verificado por meio dos resultados obtidos durante a avaliação dos acessos no CNPGC, em que este capim produziu 33 t/ha.ano de MS e teve, em média, $80 \%$ de folhas, $12,7 \%$ de proteína bruta nas folhas e $9 \%$ nos colmos (SAVIDAN et al., 1990; JANK et al., 1994; SANTOS et al., 1999).

O estudo foi realizado com o objetivo de verificar o efeito de três sistemas de pastejo rotacionado: isolado, simultâneo e alternado de ovinos com bovinos, sobre características estruturais e bromatológicas do capim Tanzânia.

\section{MATERIAL E MÉTODOS}

O trabalho foi realizado no Centro de Manejo de Ovinos da Fazenda Água Limpa, da Universidade de Brasília, localizada no Distrito Federal (15\%57' de latitude e $47^{\circ} 56^{\prime}$ de longitude oeste), onde o tipo climático é Tropical Estacional (Aw), segundo classificação de Koeppen, com estacionalidade do traditional sheep rearing systems in the Brazilian savannah region.

regime de chuvas, invernos secos e verões chuvosos. A pluviosidade anual varia entre 1.500 a $1.900 \mathrm{~mm}$. O experimento teve duração de 84 dias no período chuvoso, compreendida entre janeiro a abril de 2008.

A área experimental foi formada no final do ano de 2007, após análise, correção e adubação do solo, onde pastagens de capim Tanzânia foram estabelecidas em 5,2 ha e subdivididas em treze piquetes de aproximadamente 0,4 ha cada, nos quais três sistemas de manejo foram instalados: BO Pastejo simultâneo de bovinos com ovinos no mesmo piquete; BDO - Pastejo alternado: primeiro pelos bovinos, depois pelos ovinos e $\mathrm{O}$ - Pastejo isolado de ovinos. Foram destinados quatro piquetes para os sistemas (BO e $\mathrm{O}$ ) e cinco para o $\mathrm{BDO}$, para que pudesse ser realizado o pastejo rotacionado, com sete dias de ocupação e 21 dias de descanso. No sistema BDO sempre havia dois piquetes em uso simultâneo, um com bovinos e outro com ovinos. Foi feito o preparo, correção e adubação do solo na área da pastagem, de acordo com MARTHA et al. (2007), e quantidade de sementes viáveis por hectare, segundo recomendações da Embrapa. A subdivisão em piquetes foi feita através de cerca elétrica com dois fios eletrificados e dois fios terra.

Após a saída dos ovinos dos piquetes, no primeiro ciclo de pastejo, foi feita uma adubação nitrogenada de cobertura utilizando-se como fertilizante a uréia, equivalente a uma dose a $100 \mathrm{~kg}$ de N/ha aplicada a lanço em dose única.

$\mathrm{O}$ experimento foi desenvolvido em delineamento inteiramente casualizado, em esquema fatorial $3 \times 3$, e as fontes de variação foram os sistemas de pastejo e os ciclos de pastejo, com 4 repetições para cada tratamento, sendo que cada piquete, com área média de 0,4 ha, foi utilizado como unidade experimental.

O modelo estatístico adotado foi:

$Y_{i j}=\mu+S_{i}+C_{j}+S_{i j k}+E_{i j k}$

Em que:

$\mathrm{Y}_{\mathrm{ij}}=$ valor observado para $\mathrm{Y}$, no i-ésimo sistema de pastejo, no j-ésimo ciclo de pastejo;

$\mu=$ média geral

$\mathrm{S}_{\mathrm{i}}=$ efeito do sistema de pastejo $(\mathrm{i}=\mathrm{BO}, \mathrm{BDO}, \mathrm{O})$;

$\mathrm{C}_{\mathrm{j}}=$ efeito do ciclo de pastejo $(\mathrm{j}=1,2,3)$

$\mathrm{SC}_{\mathrm{ijk}}=$ efeito da interação entre $\left(\mathrm{S}_{\mathrm{i}} \times \mathrm{C}_{\mathrm{j}}\right)$

$\mathrm{E}_{\mathrm{ijk}}=$ erro experimental associado a $\mathrm{Y}_{\mathrm{ijk}}$

A taxa de lotação inicial foi de aproximadamente duas UA/ha, quando 30 ovinos machos inteiros da raça Santa Inês, com peso médio 
inicial de $22,70 \pm 2,23 \mathrm{~kg}$, foram distribuídos em quantidades iguais nos diferentes sistemas de pastejo. Para completar a taxa de lotação estipulada foram utilizadas 16 ovelhas adultas da raça Santa Inês, com peso médio 47,38 $\pm 7,67 \mathrm{~kg}$, no tratamento $\mathrm{O}$ e 12 bovinos mestiços, com peso médio de 206,70 $\pm 20,79$ $\mathrm{kg}$, sendo seis no tratamento BO e seis no BDO. Esses animais foram mantidos na área experimental do início ao fim do trabalho, sem a introdução de outros animais. Foi considerado que, em termos de consumo, cinco ovelhas adultas, com peso vivo de aproximadamente $50 \mathrm{~kg}$, equivalem a $1 \mathrm{UA}(450 \mathrm{~kg})$. Esta relação de 5:1 considera o peso metabólico do animal e não o peso vivo, uma vez que animais menores produzem mais calor e consomem mais alimento por unidade de peso vivo que animais de porte maior (CARVALHO et al., 2005). O peso metabólico de uma vaca de $450 \mathrm{~kg}$ equivale a $97,7 \mathrm{~kg}$, enquanto o de uma ovelha de $50 \mathrm{~kg}$ equivale a 18,8 $\mathrm{kg}$, ou seja, uma relação de aproximadamente 1:5 (vaca:ovelha).

Os ovinos receberam $200 \mathrm{~g} / \mathrm{animal} / \mathrm{dia}$ de mistura concentrada composta por $55 \%$ de milho triturado, $30 \%$ de farelo de soja, $10 \%$ de farelo de algodão e $5 \%$ de farelo de trigo, com teores de $88 \%$ de matéria seca, $22 \%$ proteína bruta, $72 \%$ de nutrientes digestíveis totais e 2,613 Mcal $/ \mathrm{kg}$ de energia metabolizável, objetivando obter um ganho médio de aproximadamente $110 \mathrm{~g} / \mathrm{animal} / \mathrm{dia}$, segundo recomendação do NRC (2007). A categoria dos bovinos recebeu $2 \mathrm{~kg} / \mathrm{animal} / \mathrm{dia}$ de mistura concentrada composta por $60 \%$ de milho $+40 \%$ farelo de soja, com teores de $88 \%$ de matéria seca, $23 \%$ de proteína bruta, $78 \%$ de nutrientes digestíveis totais e $2,839 \mathrm{Mcal} / \mathrm{kg}$ de energia metabolizável. Além disto, foram fornecidos sais minerais específicos à vontade para cada espécie, tomando-se o cuidado de evitar o acesso ao sal de uma espécie pela outra: o sal dos bovinos, pela altura do cocho, e o dos ovinos, colocando-o na baia de pernoite dos animais, onde eram recolhidos diariamente. A água também foi disponibilizada à vontade.

A forragem foi colhida semanalmente nos piquetes de entrada e saída dos animais com a finalidade de estimar a disponibilidade de massa de forragem por ciclo de pastejo. Em cada piquete foram obtidas 4 amostras representativas, colhidas a uma altura de aproximadamente $5 \mathrm{~cm}$ do solo, em retângulos de 0,5 x $1,0 \mathrm{~m}$, as quais eram acondicionadas em um saco plástico e, juntas, formaram uma amostra composta. Essa amostra foi pesada e, assim, obtido o peso da massa de forragem por ciclo de pastejo, disponível em $2 \mathrm{~m}^{2}$, estimando-se proporcionalmente a disponibilidade em um hectare.
Após a pesagem da amostra composta colhida no momento de entrada dos animais, o material foi colocado sobre uma lona, para que fosse misturado e daí fossem retiradas duas sub-amostras, uma para a determinação de matéria seca e outra para proceder à separação em folhas, colmos e material morto. Essas sub-amostras foram acondicionadas em sacos plásticos, devidamente vedados e identificados. Em seguida, foram conduzidos ao laboratório de nutrição animal da Fazenda Água Limpa, da UnB, para a realização das análises.

No sistema BDO, as amostras da forragem foram colhidas em dois momentos, na entrada dos bovinos em cada piquete e na saída dos bovinos/entrada dos ovinos, para que pudessem ser avaliadas as características da forragem nesses dois momentos dentro do sistema BDO, bem como avaliar o efeito dos três sistemas sobre as características da forragem disponibilizada aos ovinos.

A determinação absoluta e relativa dos componentes folha, colmo e material morto nas amostras de forragem foi feita por separação dos mesmos, que eram acondicionados em sacos de papel e, em seguida, levados para secagem em estufa de circulação de ar forçado a $55-60^{\circ} \mathrm{C}$, por 72 horas, sendo posteriormente pesados e determinadas suas proporções na matéria seca.

Foi coletada uma amostra de capim de cada piquete, imediatamente antes da entrada dos animais, simulando o pastejo, na qual foram analisados os conteúdos de fibra em detergente neutro e fibra em detergente ácido, utilizando-se a metodologia proposta por VAN SOEST et al. (1991), e os teores de: matéria seca, proteína bruta, extrato etéreo, fósforo inorgânico e matéria mineral, conforme descrições feitas por SILVA \& QUEIROZ (2002).

O teor de nutrientes digestíveis totais (NDT) foi calculado, segundo a metodologia proposta por CAPPELLE et al. (2001), pela Equação 1: $\mathrm{NDT}=9,6086-0,669233 \mathrm{FDN}+0,437932$ $\mathrm{PB}\left(\mathrm{R}^{2}=0,71\right) \quad$ [Eq.1]

O pacote estatístico SAS (1999) foi utilizado para realização de todos os procedimentos de análise, adotando-se o procedimento GLM (análise de variância). O teste adotado para comparações entre médias das demais variáveis foi o teste de Tukey, a 10 \% de significância.

\section{RESULTADOS E DISCUSSÃO}

A precipitação pluviométrica durante $\mathrm{o}$ período experimental foi de $924,7 \mathrm{~mm}$, e a temperatura média foi de aproximadamente $21,6{ }^{\circ} \mathrm{C}$ (Tabela 1). 
Tabela 1 - Precipitação e temperatura na área experimental nos meses de duração do experimento

\begin{tabular}{llllll}
\hline \multirow{2}{*}{ Mês } & \multicolumn{4}{l}{ Precipitação $(\mathrm{mm})$} & \multicolumn{3}{l}{ Temperatura $\left({ }^{\circ} \mathrm{C}\right)$} \\
\cline { 2 - 6 } & Média & Total & Média & Máx & Mín \\
\hline Janeiro & 9,6 & 297,4 & 21,8 & 27,4 & 16,1 \\
Fevereiro & 9,5 & 266,7 & 21,8 & 27,4 & 16,2 \\
Março & 8,3 & 257,6 & 21,4 & 27,1 & 15,7 \\
Abril & 6,4 & 191,8 & 21,5 & 28,1 & 14,9 \\
\hline
\end{tabular}

Todas as variáveis avaliadas foram dias e a dose de nitrogênio aplicada foi de $100 \mathrm{~kg} / \mathrm{ha}$, influenciadas pelos ciclos de pastejo e houve aplicada uma única vez, após a saída dos ovinos dos interação entre sistema de pastejo e ciclo de pastejo piquetes no primeiro ciclo de pastejo. SANTOS et al. para as variáveis: proporção de colmo, proteína (1999), trabalhando com pastagens de capim bruta, extrato etéreo e nutrientes digestíveis totais Tanzânia pastejadas por novilhas da raça holandesa, (Tabela 2).

A massa de forragem disponível por ciclo de pastejo (MFP) foi semelhante para os três sistemas de pastejo. Alguns fatores, tais como frequência de pastejo e adubação nitrogenada, interferem diretamente sobre essa variável. Neste experimento, a frequência com que os animais retornavam ao mesmo piquete para consumir a forragem foi de 21 verificaram uma correlação positiva entre a frequência de pastejo e a disponibilidade de massa de forragem por ciclo de pastejo. Esses autores adotaram 28 dias de descanso, três dias de ocupação e adubação nitrogenada de $400 \mathrm{~kg} / \mathrm{ha}$ dividida em seis aplicações, o que pode explicar maiores disponibilidades de massa de forragem por ciclo de pastejo $(4.486 \mathrm{~kg} / \mathrm{ha})$ que as deste experimento.

Tabela 2 - Resumo da análise de variância para as características estruturais: MFP - massa de forragem por ciclo de pastejo; PF - proporção de folha; $\mathrm{PC}$ - proporção de colmo; PMM - proporção de material morto; F/C - relação folha:colmo; e bromatológicas do capim Tanzânia (MS - Matéria Seca; MM - Matéria Mineral; PB - Proteína Bruta; EE - extrato etéreo; FDN - fibra em detergente neutro; FDA - fibra em detergente ácido; $\mathrm{Pi}$ - fósforo inorgânico e NDT - nutrientes digestíveis totais)

\begin{tabular}{lllll}
\hline & $\begin{array}{l}\text { Sistema de } \\
\text { pastejo }\end{array}$ & $\begin{array}{l}\text { Ciclo de } \\
\text { pastejo }\end{array}$ & $\begin{array}{l}\text { Sistema de pastejo } \\
\text { Ciclo de pastejo }\end{array}$ & CV $(\%)$ \\
\hline $\mathrm{MFP}(\mathrm{kg} / \mathrm{ha})$ & $\mathrm{ns}$ & $* * *$ & $\mathrm{~ns}$ & 15,26 \\
$\mathrm{PF}^{1}$ & $\mathrm{~ns}$ & $* *$ & $\mathrm{~ns}$ & 13,83 \\
$\mathrm{PC}^{1}$ & $\mathrm{~ns}$ & $* *$ & $\mathrm{p}<0,10$ & 12,64 \\
$\mathrm{PMM}^{1}$ & $\mathrm{~ns}$ & $*$ & $\mathrm{~ns}$ & 32,35 \\
$\mathrm{~F} / \mathrm{C}^{1}$ & $\mathrm{p}<0,10$ & $* *$ & $\mathrm{~ns}$ & 19,68 \\
$\mathrm{MS}^{1}$ & $\mathrm{~ns}$ & $* *$ & $\mathrm{~ns}$ & 6,89 \\
$\mathrm{MM}^{1}$ & $\mathrm{~ns}$ & $*$ & $\mathrm{~ns}$ & 8,32 \\
$\mathrm{~PB}^{1}$ & $\mathrm{~ns}$ & $* * *$ & $*$ & 9,80 \\
$\mathrm{EE}^{1}$ & $\mathrm{~ns}$ & $* * *$ & $*$ & 6,88 \\
$\mathrm{FDN}^{1}$ & $\mathrm{p}<0,10$ & $\mathrm{p}<0,10$ & $\mathrm{~ns}$ & 3,10 \\
$\mathrm{FDA}^{1}$ & $\mathrm{~ns}$ & $* * *$ & $\mathrm{~ns}$ & 3,80 \\
$\mathrm{Pi}^{1}$ & $\mathrm{~ns}$ & $* *$ & $\mathrm{~ns}$ & 27,57 \\
$\mathrm{NDT}^{1}$ & $*$ & $* * *$ & $* *$ & 4,66 \\
\hline
\end{tabular}

\footnotetext{
${ }^{1} \%$ na MS; CV: coeficiente de variação *p<0,05; **p<0,01; ***p<0,001; ns: não significativo
} 
A parte mais nobre, destinada ao consumo dos ruminantes, refere-se à proporção de folhas, sendo que, para essa variável, a pastagem submetida ao sistema de BO foi superior ao BDO, não havendo, entretanto, diferença em relação ao sistema $\mathrm{O}$ (Tabela 3). Isso demonstra que nos sistemas BO e O houve um melhor aproveitamento da forragem, uma vez que, com a mesma produção de matéria seca, a forragem disponível para os animais foi mais rica em folhas, onde está concentrada a maior parte dos nutrientes digestíveis. Tal diferença pode ser explicada pelo fato de que, no simultâneo e no isolado, a taxa de lotação instantânea foi maior durante o período de ocupação, pois todos os animais, alocados nos respectivos sistemas de pastejo consumiam a forragem disponível em uma semana, enquanto que no alternado um mesmo piquete ficava ocupado por 14 dias consecutivos, sete dias pela categoria de bois e sete pelos ovinos. Há que se lembrar que, no sistema BDO, como os bovinos já haviam passado pelo piquete em que os ovinos teriam acesso, boa parte das folhas já tinha sido consumida, restando aos ovinos uma forragem de pior qualidade.

Tabela 3 - Médias das características estruturais: MFP - massa de forragem por ciclo de pastejo; PF proporção de folha; PC - proporção de colmo; PMM - proporção de material morto; F/C - relação folha:colmo; e bromatológicas do capim Tanzânia: (MS - Matéria Seca; PB -Proteína Bruta; FDN -fibra em detergente neutro; FDA - fibra em detergente ácido; EE - extrato etéreo; MM -Matéria Mineral; Pi fósforo inorgânico e NDT - nutrientes digestíveis totais, em diferentes sistemas de pastejo)

\begin{tabular}{|c|c|c|c|c|}
\hline \multirow[b]{2}{*}{ VARIÁVEIS } & \multicolumn{3}{|c|}{ SISTEMAS DE PASTEJO } & \multirow[t]{2}{*}{$\mathrm{CV}(\%)$} \\
\hline & $\mathrm{BO}$ & BDO* & $\mathrm{O}$ & \\
\hline MFP (kg/ha) & 3200,48 & 3176,16 & 3672,19 & 15,26 \\
\hline $\mathrm{PF}^{1}$ & $61,69^{a}$ & $51,62^{\mathrm{b}}$ & $57,20^{a b}$ & 13,83 \\
\hline $\mathrm{PC}^{1}$ & 25,52 & 29,88 & 28,59 & 12,64 \\
\hline $\mathrm{PMM}^{1}$ & 12,80 & 18,50 & 14,21 & 32,35 \\
\hline $\mathrm{F} / \mathrm{C}$ & $2,75^{\mathrm{a}}$ & $1,90^{\mathrm{b}}$ & $2,23^{\mathrm{ab}}$ & 19,68 \\
\hline $\mathrm{MS}^{1}$ & 22,96 & 24,93 & 23,09 & 6,89 \\
\hline $\mathrm{PB}^{1}$ & $15,80^{\mathrm{a}}$ & $12,05^{\mathrm{b}}$ & $15,14^{\mathrm{a}}$ & 8,32 \\
\hline $\mathrm{FDN}^{1}$ & $67,03^{\mathrm{b}}$ & $70,34^{\mathrm{a}}$ & $67,13^{\mathrm{b}}$ & 9,80 \\
\hline FDA $^{1}$ & $37,26^{a b}$ & $39,22^{\mathrm{a}}$ & $36,84^{b}$ & 6,88 \\
\hline $\mathrm{EE}^{1}$ & 2,59 & 2,45 & 2,54 & 3,10 \\
\hline $\mathrm{MM}^{1}$ & 8,91 & 8,74 & 8,52 & 3,80 \\
\hline $\mathrm{Pi}^{1}$ & 0,27 & 0,25 & 0,25 & 27,57 \\
\hline $\mathrm{NDT}^{1}$ & $53,67^{\mathrm{a}}$ & $49,81^{\mathrm{b}}$ & $53,31^{\mathrm{a}}$ & 4,66 \\
\hline
\end{tabular}

${ }^{1} \%$ na MS; CV - coeficiente de variação; Médias seguidas de diferentes letras em uma mesma linha diferem (P<0.10) entre si, segundo o teste de Tukey. BO - bovinos e ovinos; BDO - bovinos primeiro depois ovinos; O - ovinos.

Em contraposição, a quantidade de colmo, mais fibrosa e menos digestível, deve ser evitada na pastagem. Essa variável não apresentou diferença significativa entre os sistemas de pastejo. PARSONS et al. (1988) ressaltam a importância de se controlar a produção de hastes no pasto. A presença de grandes quantidades de hastes pode comprometer a eficiência do sistema de duas formas: limitando a capacidade de colheita pelo animal ou reduzindo seu valor alimentar.

Seguindo o comportamento observado na proporção de folhas, a relação folha:colmo na pastagem submetida ao sistema BO apresentou melhor resultado, em relação ao $\mathrm{BDO}$, não havendo diferença entre $\mathrm{O}$ e os demais. Quanto maior essa relação, melhor a digestibilidade da matéria seca nos diferentes genótipos de $P$. maximum, conforme observado por SINGH (1995). Além disso, a elevada proporção de hastes pode limitar o consumo dos animais (FLORES et al., 1993). Segundo PINTO et al. (1994), valores inferiores a 1 nessa relação interferem de forma negativa no consumo pelos 
ruminantes. Em todos os sistemas avaliados, essa relação foi superior a 1, situação que se reflete nos dados de consumo pelos ovinos que não foram significativamente diferentes. Deve-se enfatizar aqui a excelente capacidade do Tanzânia em desenvolver mais folhas em detrimento de colmos, característica de grande interesse na nutrição dos ruminantes.

$\mathrm{Na}$ avaliação da qualidade da forragem, os dados referentes aos teores de proteína bruta (PB), fibras em detergente neutro (FDN) e ácido (FDA) e nutrientes digestíveis totais (NDT), corroboram com os resultados observados na melhor relação folha:colmo do sistema BO em detrimento ao BDO. Embora para a relação folha:colmo o sistema $\mathrm{O}$ não tenha sido significativamente superior ao BDO, na avaliação bromatológica o isolado demonstrou ser superior ao alternado com maiores quantidades de proteína e nutrientes digestíveis totais e menores teores de fibra, conferindo melhor qualidade à massa de forragem disponível aos animais.

Segundo NOLAN \& CONNOLY (1977), a exploração mista de bovinos com ovinos produz efeitos nas variáveis da interface planta-animal. Os autores concluíram que esse tipo de exploração aumenta a produção por área e por animal em comparação à utilização da forragem com apenas uma espécie. Tal efeito estaria relacionado a três consequências dessa exploração: aumento da produção da pastagem, melhoria da qualidade da forragem e da eficiência da utilização (NOLAN \& CONNOLY, 1989). Segundo BAKER (1985) e NOLAN \& CONNOLY (1989), a origem desse efeito positivo estaria na complementaridade dos padrões de pastejo, associados com as distintas preferências de cada espécie animal por diferentes plantas, partes das plantas ou localizações geográficas. Neste experimento, o que pôde ser observado foi a preferência por partes da planta e pela localização geográfica, uma vez que a forragem refugada pelos bovinos, ao redor das placas de fezes por eles depositadas, foi consumida pelos ovinos.

Além disso, destaca-se a excelente qualidade da forragem produzida ao redor da área de dejeção dos bovinos. NOLAN \& CONNOLY (1989) encontraram em áreas de pastejo isolado de bovinos o percentual de $5 \%$ de área sob as dejeções e $15 \%$ da área como rejeitada (plantas altas em torno das placas de dejeção). Essa pequena área continha até $44 \%$ da forragem total disponível e concentrava $40 \%$ do total de fósforo e potássio, devido ao fato de uma placa de fezes de bovino equivaler a uma aplicação de $1040 \mathrm{~kg}$ de N/ha, $400 \mathrm{~kg}$ de $\mathrm{k} / \mathrm{ha}$ e $280 \mathrm{~kg}$ de $\mathrm{P} / \mathrm{ha}$ (WILLIANS \& HAYNES, 1995). Os autores verificaram ainda que: os bovinos rejeitam as plantas altas por, no mínimo, três semanas após a dejeção; a preferência dos ovinos por essas plantas é aproximadamente duas vezes em relação aos bovinos; as plantas altas tem aproximadamente quatro unidades percentuais de digestibilidade a mais em pastejo misto.

As forragens tradicionais na criação de ovinos e bovinos no Centro-Oeste tem sido o Andropogon, cujos teores de proteína nas águas tem sido ao redor de $7 \%$, e Braquiária na criação de bovinos, com $8 \%$ de PB. Os valores aqui obtidos para o Tanzânia foram superiores, denotando que, além de produção de massa, a quantidade de proteína dessa massa foi bastante satisfatória. Há que se evidenciar que tais dados referem-se à pastagem recém implantada de primeiro pastejo.

Os teores de FDN e FDA estão de acordo com as pastagens tropicais e aqueles obtidos por CANO et al. (2004) e BALSALOBRE (2002) com Tanzânia, cujos valores de FDN estiveram entre 63,6 e 69,0\%. Segundo VAN SOEST (1982), as fibras são constituídas pela fração menos digestível da forragem, comprometendo, assim, a qualidade do material e são a principal fonte de energia para o ruminante, a qual, em ação sinérgica com a proteína, deve garantir o desempenho animal.

Os minerais, juntamente com as vitaminas, também têm funções essenciais na nutrição dos ruminantes. Os teores de matéria mineral não diferiram entre si e estão dentro dos parâmetros apresentados por BALSALOBRE (2002) de 7,87 a $10,47 \%$ na matéria seca. Segundo o autor, há uma tendência de altos teores de matéria mineral em forrageiras tropicais adubadas. A concentração de fósforo nos três sistemas de pastejo apresentou valores acima dos encontrados normalmente em pastagens tropicais. CARVALHO et al. (2005), ao revisarem vários trabalhos na literatura brasileira, demonstraram que os teores de fósforo na matéria seca da parte aérea de gramíneas tropicais variaram de 0,07 a $0,20 \%$, com apenas $14 \%$ delas com nível superior a $0,18 \%$, sendo $86 \%$ das gramíneas deficientes para atender às exigências animais. Entretanto, pastagens bem manejadas apresentaram teores acima de $0,18 \%$ de $\mathrm{P}$ no verão. Esses autores afirmaram que o teor desse mineral decresce com o aumento da idade da forrageira, o que pode ser agravado pela época do ano e pela parte da planta em questão, sendo as folhas mais ricas que o caule nesse elemento. Conforme já discutido, na área experimental houve adubação nitrogenada e fosfatada, o que pode ter garantido a excelente qualidade da pastagem utilizada.

Pelo menos dois sistemas de pastejo diferiram entre si, quanto à proporção de colmo no terceiro ciclo de pastejo, aos teores de PB no segundo e terceiro ciclos, EE no segundo e no quarto ciclos e NDT no primeiro e segundo ciclo (Tabela 4). 
Tabela 4 - Resumo da análise de variância para as variáveis: proporção de colmo (PC), proteína bruta (PB), extrato etéreo (EE) e nutrientes digestíveis totais (NDT), estudados e comparados pelo teste de Tukey a 10\%, de acordo com o ciclo de pastejo

\begin{tabular}{|c|c|c|c|c|}
\hline \multirow[b]{2}{*}{ CICLO DE PASTEJO } & \multicolumn{4}{|c|}{ VARIÁVEIS } \\
\hline & $\begin{array}{c}\mathrm{PC} \\
(\% \text { na } \mathrm{MS})\end{array}$ & $\begin{array}{c}\mathrm{PB} \\
(\% \text { na } \mathrm{MS})\end{array}$ & $\begin{array}{c}\mathrm{EE} \\
(\% \text { na } \mathrm{MS})\end{array}$ & $\begin{array}{c}\text { NDT } \\
(\% \text { na } \mathrm{MS})\end{array}$ \\
\hline 1 & ns & $\mathrm{ns}$ & ns & $*$ \\
\hline 2 & $\mathrm{~ns}$ & $* * *$ & $\mathrm{p}<0,10$ & $* *$ \\
\hline 3 & $*$ & $*$ & $\mathrm{~ns}$ & ns \\
\hline
\end{tabular}

No detalhamento da análise de variância por ciclos de pastejo (Tabela 5) observa-se que, como visto anteriormente, a pastagem do sistema BDO apresentou maior proporção de colmo, embora somente no terceiro ciclo, afetando sobremaneira as características nutricionais, com redução de PB e aumento de fibra, indicando que o pasto nesse sistema apresentou qualidade inferior aos demais.

As médias de NDT ao longo do período experimental para os sistemas $\mathrm{BO}$ e $\mathrm{O}$ foram semelhantes e superiores ao BDO, contribuindo para uma melhor qualidade nutricional do capim oferecido aos animais dos sistemas simultâneo e isolado em detrimento do alternado. Segundo CAPPELLE et al. (2001), o aumento no teor de PB afeta positivamente o teor de nutrientes digestíveis totais, enquanto os teores de fibra em detergente neutro e ácido são inversamente proporcionais ao NDT. Além desses componentes químicos da planta forrageira, a maior proporção de folhas, onde se concentra a maior parte dos nutrientes digestíveis, também contribui para o aumento do teor de NDT e da digestibilidade do volumoso oferecido.

Tabela 5 - Médias da proporção de colmo (PC) e teores de proteína bruta (PB), extrato etéreo (EE), fibra em detergente ácido (FDA) e nutrientes digestíveis totais (NDT) nos diversos sistemas de pastejo em diferentes ciclos de pastejo, comparadas pelo teste de Tukey a $10 \%$

\begin{tabular}{|c|c|c|c|c|c|}
\hline \multirow[t]{2}{*}{ Variável } & \multirow{2}{*}{$\begin{array}{l}\text { CICLO DE } \\
\text { PASTEJO }\end{array}$} & \multicolumn{3}{|c|}{ SISTEMAS DE PASTEJO } & \multirow{2}{*}{$\mathrm{CV}(\%)$} \\
\hline & & $\mathrm{BO}$ & $\mathrm{BDO}$ & $\mathrm{O}$ & \\
\hline $\mathrm{PC}^{1}$ & 3 & $20,46^{b}$ & $30,48^{\mathrm{a}}$ & $21,29^{b}$ & 5,77 \\
\hline \multirow{2}{*}{$\mathrm{PB}^{1}$} & 2 & $17,84^{\mathrm{a}}$ & $13,22^{b}$ & $21,13^{\mathrm{a}}$ & 6,08 \\
\hline & 3 & $18,76^{\mathrm{a}}$ & $13,58^{b}$ & $17,08^{\mathrm{a}}$ & 6,18 \\
\hline $\mathrm{EE}^{1}$ & 2 & $2,70^{a b}$ & $2,52^{\mathrm{b}}$ & $3,16^{\mathrm{a}}$ & 5,90 \\
\hline \multirow{2}{*}{ NDT $^{1}$} & 1 & $51,09^{\mathrm{a}}$ & $45,02^{b}$ & $48,29^{a b}$ & 5,77 \\
\hline & 2 & $54,52^{\mathrm{b}}$ & $50,65^{\mathrm{c}}$ & $58,78^{\mathrm{a}}$ & 3,92 \\
\hline
\end{tabular}

${ }^{1} \%$ na MS; CV - coeficiente de variação; Médias seguidas de diferentes letras em uma mesma linha diferiram $(\mathrm{P}<0.10)$ entre si, segundo o teste de Tukey. BO - bovinos e ovinos; BDO - bovinos depois ovinos; $\mathrm{O}$ - ovinos.

Os teores de fibra em detergente ácido foram semelhantes aos resultados encontrados em amostras de pastejo simulado por BALSALOBRE (2002) e CANO et al (2004). Segundo esses autores, os níveis de FDA em capim Tanzânia podem atingir níveis acima de $40 \%$ somente em plantas com idade fisiológica bem avançada.

Foram comparadas as variáveis estruturais e bromatológicas do capim, referentes aos dois momentos de uso dos piquetes do grupo BDO entrada dos bovinos (E) e entrada dos ovinos/ saída dos bovinos $(E / S)$ - de forma a verificar se houve diferenças entre os parâmetros avaliados nesses dois momentos, bem como se houve ou não interação entre o momento e o ciclo de pastejo.

O resumo da análise de variância (Tabela 6) 
demonstra que houve diferença significativa entre os dois momentos de uso, em pelo menos um dos ciclos de pastejo, para as variáveis: massa de forragem disponível por ciclo de pastejo e teor de proteína bruta. Essas duas variáveis são determinantes para o desempenho dos animais a pasto, afetando inclusive sua capacidade imunológica.
As variáveis proporção de folha, proporção de colmo, relação folha:colmo e teor de fibra em detergente ácido foram influenciados pelo momento de uso e pelo ciclo de pastejo denotando que o manejo adotado no sistema de pastejo BDO resultou em modificações na estrutura do capim oferecido primeiramente aos bovinos e em seguida aos ovinos.

Tabela 6 - Resumo da análise de variância para as características estruturais: MFP - massa de forragem por ciclo de pastejo; PF - proporção de folha; PC - proporção de colmo; PMM - proporção de material morto; F/C - relação folha:colmo; e bromatológicos do capim Tanzânia (MS - Matéria Seca; MM - Matéria Mineral; PB - Proteína Bruta; EE - extrato etéreo; FDN - fibra em detergente neutro; FDA - fibra em detergente ácido; $\mathrm{Pi}$ - fósforo inorgânico e NDT - nutrientes digestíveis totais)

\begin{tabular}{lllll}
\hline & $\begin{array}{l}\text { Momentos } \\
\text { de uso }\end{array}$ & $\begin{array}{l}\text { Ciclo de } \\
\text { pastejo }\end{array}$ & $\begin{array}{l}\text { Momentos * Ciclo } \\
\text { de pastejo }\end{array}$ & CV $(\%)$ \\
\hline $\mathrm{MFP}(\mathrm{kg} / \mathrm{ha})$ & $\mathrm{ns}$ & $* * *$ & $\mathrm{P}<0,10$ & 25,82 \\
$\mathrm{PF}^{1}$ & $\mathrm{p}<0,10$ & $*$ & $\mathrm{~ns}$ & 18,15 \\
\hline $\mathrm{PC}^{1}$ & $* *$ & $\mathrm{p}<0,10$ & $\mathrm{~ns}$ & 22,09 \\
$\mathrm{PMM}^{1}$ & $\mathrm{~ns}$ & $\mathrm{p}<0,10$ & $\mathrm{~ns}$ & 45,70 \\
$\mathrm{~F} / \mathrm{C}^{1}$ & $*$ & $*$ & $\mathrm{~ns}$ & 39,47 \\
$\mathrm{MS}^{1}$ & $\mathrm{~ns}$ & $* *$ & $\mathrm{~ns}$ & 12,44 \\
$\mathrm{MM}^{1}$ & $\mathrm{~ns}$ & $\mathrm{~ns}$ & $\mathrm{~ns}$ & 71,82 \\
$\mathrm{~PB}^{1}$ & $\mathrm{p}<0,10$ & $* * *$ & $* *$ & 13,54 \\
$\mathrm{EE}^{1}$ & $\mathrm{~ns}$ & $*$ & $\mathrm{~ns}$ & 16,67 \\
$\mathrm{FDN}^{1}$ & $\mathrm{~ns}$ & $*$ & $\mathrm{~ns}$ & 3,99 \\
$\mathrm{FDA}^{1}$ & $\mathrm{p}<0,10$ & $* *$ & $\mathrm{~ns}$ & 9,69 \\
$\mathrm{Pi}^{1}$ & $\mathrm{~ns}$ & $\mathrm{~ns}$ & $\mathrm{~ns}$ & 46,08 \\
$\mathrm{NDT}^{1}$ & $\mathrm{~ns}$ & $* * *$ & $\mathrm{~ns}$ & 4,58 \\
\hline
\end{tabular}

${ }^{1} \%$ na MS; *p $<0,05 ; * * p<0,01 ; * * * p<0,001 ;$ ns - não significativo.

Os dois momentos de uso apresentaram diferenças significativas quanto à massa de forragem disponível somente no primeiro ciclo de pastejo e quanto ao teor de proteína bruta no segundo e terceiro ciclos de pastejo (Tabela 7).

Tabela 7 - Resumo da análise de variância para as variáveis massa de forragem por ciclo de pastejo (MFP) e proteína bruta $(\mathrm{PB})$ nos diversos ciclos de pastejo.

\begin{tabular}{lll}
\hline CICLO DE PASTEJO & VARIÁVEIS & \\
\cline { 2 - 3 } & MFP & PB \\
& $(\mathrm{kg} / \mathrm{ha})$ & $(\%$ na MS $)$ \\
\hline 1 & $* *$ & $\mathrm{~ns}$ \\
2 & $\mathrm{~ns}$ & $* *$ \\
3 & $\mathrm{~ns}$ & $*$ \\
\hline
\end{tabular}

$* \mathrm{p}<0,05 ; * * \mathrm{p}<0,01 ;$ ns: não significativo. 
Tabela 8 - Médias da massa de forragem por ciclo de pastejo e teores de proteína bruta (PB), nos diversos momentos de uso do sistema de pastejo BDO, em diferentes ciclos de pastejo, comparadas pelo teste de Tukey a $10 \%$

\begin{tabular}{lllll}
\hline \multirow{2}{*}{ VARIÁVEL } & $\begin{array}{l}\text { CICLO DE } \\
\text { PASTEJO }\end{array}$ & \multicolumn{2}{l}{ MOMENTOS DE USO } & CV (\%) \\
\cline { 3 - 5 } & M & $5177,35^{\mathrm{a}}$ & $4043,16^{\mathrm{b}}$ & 6,86 \\
& 1 & & & \\
& 2 & $18,22^{\mathrm{a}}$ & $13,22^{\mathrm{b}}$ & 11,18 \\
$\mathrm{~PB}^{1}$ & 3 & $17,55^{\mathrm{a}}$ & $13,58^{\mathrm{b}}$ & 9,89 \\
\hline
\end{tabular}

\% na MS; CV - coeficiente de variação; Médias seguidas de diferentes letras em uma mesma linha diferiram $(\mathrm{P}<0.10)$ entre si, segundo o teste de Tukey. E - entrada dos bovinos; E/S - entrada dos ovinos e saída dos bovinos.

O percentual de PB foi em média $34 \%$ maior nos momentos de entrada dos bovinos (E), em relação aos momentos de entrada dos ovinos e saída dos bovinos (E/S) (Tabela 8). Essa diferença colocou os ovinos submetidos ao sistema BDO em desvantagem em relação àqueles submetidos aos demais sistemas, que apresentaram médias de proteína bruta semelhantes ao momento de uso E em BDO. Além disso, TORRES et al. (2009) encontraram nesse sistema de pastejo a maior carga parasitária na pastagem e nos ovinos submetidos ao sistema BDO, o que demanda uma maior quantidade de proteína para funções de reparo do trato gastrintestinal e funções relacionadas à imunidade, tal como produção de anticorpos, além de maiores perdas endógenas de nitrogênio. Entretanto, mesmo com níveis mais baixos de proteína na pastagem, os animais em BDO não tiveram seu desempenho afetado.

A produção de matéria seca não diferiu entre os ciclos de pastejo, exceto no primeiro ciclo, em que o momento de entrada dos bovinos apresentou maior média. Isso indica que, no geral, o fato dos bois terem acessado os piquetes antes dos ovinos não implicou em perda de quantidade. Esse fato pode ter sido devido ao período de ocupação ser de sete dias, tendo uma produção de massa de capim considerável nesse intervalo de tempo, não havendo, portanto, diferença na quantidade de matéria seca disponível quando da entrada e saída dos bovinos.

Na Tabela 9 são apresentadas as médias das proporções de folha e de colmo, da relação folha:colmo e do teor de fibra em detergente ácido nos dois momentos de uso dos piquetes do sistema BDO.

Tabela 9 - Médias das proporções de folha (PF) e colmo (PC), relação folha:colmo (F/C) e teor de fibra em detergente ácido nos dois momentos de uso da forragem do sistema BDO, em \% na MS

\begin{tabular}{llll}
\hline VARIÁVEL & \multicolumn{2}{l}{ MOMENTOS DE USO } & CV (\%) \\
\cline { 2 - 3 } & E & E/S & 18,15 \\
PF & $60,11^{\mathrm{a}}$ & $51,19^{\mathrm{b}}$ & 22,09 \\
PC & $23,02^{\mathrm{b}}$ & $30,14^{\mathrm{a}}$ & 39,47 \\
F/C & $2,97^{\mathrm{a}}$ & $1,88^{\mathrm{b}}$ & 9,69 \\
FDA & $37,27^{\mathrm{b}}$ & $39,73^{\mathrm{a}}$ & \\
\hline
\end{tabular}

Médias seguidas de diferentes letras em uma mesma linha diferiram $(\mathrm{P}<0.10)$ entre si, segundo o teste de Tukey ao nível de $10 \%$. E momento de entrada dos bovinos; $\mathrm{S} / \mathrm{E}$ - momento de saída dos bovinos e entrada dos ovinos.

O arranjo estrutural da planta com menor relação folha:colmo dificulta a apreensão pelos animais. Além disso, com um maior teor de FDA e menor de proteína bruta, a digestibilidade da dieta fica prejudicada, podendo interferir no desempenho animal. CARVALHO \& MORAES (2005) afirmam que as características das refeições e a magnitude do consumo obtido são reflexos diretos da qualidade, quantidade e estrutura do pasto que é oferecido ao animal. 


\section{CONCLUSÕES}

Os tratamentos $\mathrm{BO}$ e $\mathrm{O}$ apresentaram menores valores para as variáveis PC e FDN, ao mesmo tempo em que foram superiores em $\mathrm{F} / \mathrm{C}, \mathrm{PB}$, EE e NDT em relação ao tratamento BDO, denotando melhor qualidade do capim oferecido aos ovinos nesses dois tratamentos. Portanto, o sistema de pastejo simultâneo pode ser considerado uma alternativa de manejo ao sistema isolado de ovinos na região de cerrado brasileiro.

\section{AGRADECIMENTOS}

Ao Governo do Estado do Tocantins, Secretaria de Ciência e Tecnologia-SECT e Conselho Estadual de Ciência e Tecnologia-CECT pelo apoio financeiro na execução deste trabalho.

Ao $\mathrm{CNPq}$ pelo apoio financeiro na execução deste trabalho.

\section{REFERÊNCIAS}

BALSALOBRE, M. A. A. Valor alimentar do capim tanzânia irrigado. 2002. Tese (Doutorado em Ciência Animal e Pastagens) - Escola Superior de Agricultura Luiz de Queiroz, Universidade de São Paulo, Piracicaba, $2002 . \quad$ Disponível em: <http://www.teses.usp.br/teses/disponiveis/11/11139/tde15092006-141145/>. Acesso em: 2011-11-21.

BAKER, F. H. Multispecies grazing: the state of the science. Rangelands v. 7, p. 266-269. 1985.

CANO, C. C. P.; CECATO, U.; CANTO, M. W.; SANTOS, G. T.; GALBEIRO, S.; MARTINS, E. N.; MIRA, R. T. Valor nutritivo do capim-Tanzânia (Panicum maximum Jacq. cv. Tanzânia-1) pastejado em diferentes alturas. Revista Brasileira de Zootecnia, v. 33, n.6, p.1959-1968, 2004.

CAPPELLE, E. R; VALADARES FILHO, S. C.; SILVA, J. F. C; CECON, P. R. Estimativas do valor energético a partir das características químicas e bromatológicas dos alimentos. Revista Brasileira de Zootecnia, v. 30, n. 6, p. 1837-1856, 2001.

CARVALHO, P. C. F.; RIBEIRO FILHO, H. M. N.; POLI, C. H. E. C.; MORAES, A.; DELAGARDE, R. Importância da estrutura da pastagem na ingestão e seleção de dietas pelo animal em pastejo. In: MATTOS, W. R. S. (Org.). A produção animal na visão dos brasileiros. 1 ed. Piracicaba: Fealq, 2001. p. 853-871.

CARVALHO, F. A. N; BARBOSA, F. A.; McDOWELL, L. R. Nutrição de bovinos a pasto. Belo Horizonte: PapelForm, 2003. 438p.

CARVALLHO, P. C. F.; SANTOS, D. T.; BARBOSA, C. M. P.; LUBISCO, D. S.; LANG, C. R. Otimizando o uso da pastagem pela integração de ovinos e bovinos. Anais do ZOOTEC'2005 - 24 a 27 de maio de 2005 - Campo Grande-MS. Disponível em: $<$ http://www.abz.org.br/publicacoes-tecnicas/anaiszootec/palestras/22766-Otimizando-uso-pastagem-pelaintegrao-ovinos-bovinos.html>. Acesso em: 2011-11-21.

CARVALHO, P. C. de F., GENRO, T. C. M., GONÇALVES, E. N., BAUMONT, R. A estrutura do pasto como conceito de manejo: reflexos sobre o consumo e a produtividade. In: REIS, R. A. et al. (Orgs.). Volumosos na Produção de Ruminantes, Jaboticabal, Funep. 2005, p. 107-124. Disponível em: < http://www.forragicultura.com.br/arquivos/Aestruturadopa stocomoconceitodemanejoJaboticabal2005.pdf> Acesso em: 2011-11-21.

FLORES, E. R.; LACA, E. A.; GRIGGS, T. C.; DEMMENT, M.W. Sward height and vertical morphological differentiation determine cattle bite dimensions. Agronomy Journal, v. 85, n. 3, p. 527-532, 1993.

JANK, L.; SAVIDAN, Y.; SOUZA, M. T.; COSTA, J. C. D. Avaliação do germoplasma de Panicum maximum introduzido da África. 1. Produção forrageira. Revista Brasileira de Zootecnia, v. 23, n. 3, p. 433-440, 1994.

LEMAIRE, G. Ecophysiology of grasslands: dynamics aspects of forage plant population in grazed swards. In INTERNATIONAL GRASSLAND CONGRESS, 19., 2001, São Pedro. Proceedings... São Pedro: 2001. Disponível em:< http://www.internationalgrasslands.org/files/igc/publicatio ns/2001/tema1-1.pdf> Acesso em: 2011-11-21.

MARTHA Jr., G. B.; VILELA, L.; SOUSA, D. M. G. Cerrado: uso eficiente de corretivos e fertilizantes em pastagens. 1 ed. Planaltina: Embrapa Cerrados, 2007. v. 1. $224 \mathrm{p}$.

NATIONAL RESEARCH COUNCIL. Nutrient requeriments of small ruminants. $7^{\text {th }}$ ed. Washington: National Academic Press, 2007. 408 p.

NOLAN, T.; CONNOLLY, J. Mixed stocking by sheep and steers - a review: Herbage Abstracts, v. 47, p. 367374, 1977.

NOLAN, T. Mixed grazing under nordic conditions. In:GUDMUNDSSON, O. (Ed). Grazing Reseach at Northern Latitudes. New York: Plenum Press, p. 141152, 1986.

NOLAN, T.; CONNOLLY J. Mixed v. mono-grazing by steers and sheep. Animal Production, v. 48, p. 519-533, 1989.

PARSONS, A. J.; JOHNSON, J. R.; HARVEY, A. Use of a model to optimize the interaction between frequency and severity of intermittent defoliation and to provide a fundamental comparison of the continuous and intermittent defoliation of grass. Grass and Forage Science, v. 43, p. 49-59, 1988.

PINTO, J. C.; GOMIDE, J. A.; MAESTRI, M. Produção 
de matéria seca e relação folha:caule de gramíneas forrageiras tropicais, cultivadas em vasos, com duas doses de nitrogênio. Revista Brasileira de Zootecnia, v. 23, n. 3, p. 313-326, 1994.

REIS, R. A.; RODRIGUES, L. R. A. Valor nutritivo de plantas forrageiras. Jaboticabal, FCAVJUNESP/FUNEP, 1993.

SANTOS, P. M.; BALSALOBRE, M. A. A.; CORSI, M. Efeito da frequência de pastejo e da época do ano sobre a produção e a qualidade em Panicum maximum cvs. Tanzânia e Mombaça. Revista Brasileira de Zootecnia, v. 28, p. 244-249, 1999.

S.A.S. INSTITUTE. SAS User's guide: statistics. Cary: SAS Institute, 1999.

SAVIDAN, Y. H., JANK, L., COSTA, J. C. G. Registro de 25 acessos selecionados de Panicum maximum, Campo Grande: EMBRAPA-CNPGC. (EMBRAPACNPGC, Documentos no 44) 68 p. 1990.
SILVA, D. J. ; QUEIROZ, A. C. Análise de alimentos: métodos químicos e biológicos. Viçosa, MG: Editora UFV, 2002. $235 \mathrm{p}$

SINGH, D. K. Effect of cutting management on yield and quality of different selections of guinea grass (Panicum maximum (Jacq.) L.) in a humid subtropical environment. Journal of Tropical Agriculture, v. 72, n. 3, p. 181-187. 1995.

TORRES, S. E. F. A.; McMANUS, C.; AMARANTE, A. F. T.; VERDOLIN, V.; LOUVANDINI, H. Nematóides de ruminantes em pastagem com diferentes métodos de pastejo com ovinos e bovinos. Pesquisa Agropecuária Brasileira, v. 44, n. 9, p. 1191-1197, 2009.

VAN SOEST, P. J. Nutritional ecology of the ruminant. Ithaca: Cornell University press, 1982. $374 \mathrm{p}$.

WILLIANS, P. H., HAYNES, R. J. Effect of sheep, deer and cattle dung on herbage production and soil nutrient content. Grass and Forage Science, v. 50, p. 263-271. 1995.

Protocolado em: 18 maio 2010. Aceito em: 10 nov. 2011. 